Milica J. Andevski

DOI: 10.19090/zop.2016.25.23-39

Univerzitet u Novom Sadu,

UDC: $37(4 / 9): 303.446$

Filozofski fakultet

Pregledni rad

\title{
ŠTA PRUŽAJU MEĐUNARODNE KOMPARATIVNE STUDIJE OBRAZOVNIH POSTIGNUĆA?
}

Apstrakt: Internacionalne empirijske komparativne studije realizovane proteklih godina, poznatije pod skraćenicama: PISA, TIMSS, IGLU, CIVED, „Reading Literacy”, ispituju, pre svega, rezultate, učinak (output), postignuća učenika u različitim nacionalnim školskim sistemima. U radu se govori o mogućnostima i granicama koje pružaju ove internacionalne komparativne studije postignuća, njihovim oblastima delovanja, metodičkim polazištima koja ih prate, problemima, ali i koristima koje ove studije donose, pri čemu se misli na refleksiju u javnosti, školsku i nastavnu praksu, kao i implikacije na dalja istraživanja u oblasti vaspitanja, obrazovanja i teorije obrazovanja. Rezultati ovih studija treba da najpre ministre, planere obrazovanja i političare stave u poziciju da učinak svog sistema obrazovanja uporede sa drugim kako bi bolje procenili jake i slabe strane nacionalnog sistema obrazovanja i, potom, ponudili primerenije školskoorganizaciono-obrazovno političke odluke.

Ključne reči: internacionalne komparativne studije, postignuće, sistem obrazovanja.

\section{Uvod}

Internacionalna komparacija predstavlja oblik sistematičnog dobijanja znanja, koje u pedagogiji ima dugu tradiciju i svoje mesto nalazi u oblasti izučavanja komparativne pedagogije. Sa tematskog aspekta, internacionalnom komparacijom najpre se dobija deskripcija različitih nacionalnih sistema obrazovanja, najpre njihovo sistemsko poređenje. Aspekti poređenja prate, pre svega, institucionalne strukture sistema obrazovanja; na primer, različite oblike školske strukture, podele na uzraste, završetak obrazovanja (maturu), ocenjivanje, porodični kontekst. Autori internacionalnih komparativnih istraživanja sticali su svoja saznanja najpre iz raznih izvora i dokumenata (školskih zakona, nastavnih planova i programa, školske statistike), koji su potom sistematično

\footnotetext{
${ }^{1}$ Milica Andevski, andevski@ff.uns.ac.rs
} 
obrađivani i interpretirani. Ovakvo metodičko izvođenje komparacije sistema obrazovanja u užem smislu prevaziđeno je devedesetih godina prošlog veka zahvaljujući novoj orijentaciji empirijskog karaktera. Od tada je realizovan znatno veći broj empirijskih komparativnih studija koje ispituju, pre svega, rezultate, učinak (output), postignuća u različitim nacionalnim školskim sistemima. Ako pođemo od internacionalnih komparativnih studija, u kojima su se počev od 1990. godine objavljivali rezultati povezani sa kompetencijama i veštininama učenika iz različitih zemalja, valja pomenuti TIMSS, PISA, IGLU, CIVED, „Reading Literacy“. Rezultati ovih studija dali su uporedne dokaze o znanju učenika iz različitih nacionalnih školskih sistema.

\section{Internacionalne komparativne studije}

Internacionalnu komparativnu PISA studiju, koja predstavlja u ovom trenutku najveće međunarodno istraživanje u oblasti obrazovanja, zasnovala je i realizuje je od 1997. godine organizacija OECD ("Programme for International Student Assesment”). PISA se zasniva na ispitivanju kompetencija petnaestogodišnjaka u tri domena - čitalačka pismenost, matematika i prirodne nauke - a težilo se i pregledu nivoa nekih opštih kompetencija (na primer, problemsko mišljenje, rešavanje problemskih situacija). PISA studija, osmišljena kao instrument za posmatranje sistema na duge staze i kao internacionalna komparativna studija, ponovljena je 2000, 2003, 2006, 2009, 2012. godine.

PISA je sigurno najpoznatija, ali ne i jedina internacionalna komparativna studija. Treba ovde navesti i TIMSS studiju, koja se bavi uspehom učenika različitog uzrasta u matematici i prirodnim naukama. Realizovana je i komparativna studija za osnovnu školu, kod koje su se testovi sprovodili na kraju četvrtog razreda, poznata pod skraćenicom IGLU (,Internationale Grundschul-Lese-Untersuchung” - Internacionalno ispitivanje čitanja u osnovnim školama); sprovedena je dva puta, 2001. i 2006. godine, dok su autori internacionalne komparativne studije „CivicEducation-Studie" (CIVED) utvrđivali znanje u oblasti istorije i politike (Tillmann, 2011: 107). 


\section{Metodološka koncepcija internacionalne komparacije postignuća}

Koja metodološka obeležja pokazuju ove studije? Na ovo pitanje najbolje odgovara primer metodološki posebno elaborirane PISA studije.

\section{Istraživanje kao „Sistem-Monitoring“}

Internacionalne komparativne studije su eksplicite smišljene kao „Sistem-monitoring“ kako bi se prikazale komparativne vrednosti različitih školskih sistema i tako, u suštini, procenjivao učinak (efikasnost) vlastitog sistema. Ovakav komparativni postupak već je postavljen kao instrument takmičarske, konkurentske analize u mnogim oblastima (privreda, javne službe, zdravstvo), a sada je prisutan i u oblasti obrazovanja (Weiß \& Timmermann, 2008) za prikupljanjene samo iskaza o pojedinačnimškolama ili čak razredima, nego i podataka o nacionalnim školskim sistemima. Ove studije daju komparativne rezultate koji se često odnose na ceo sistem, na postignuća učenika, ali takođe govore i o strukturama i uslovima delovanja škole i nastave. Rezultati studija nisu usmereni pojedinačno na nastavnike, nego pre svega na one koji planiraju obrazovanje, na obrazovnu politiku, na sve one koji imaju određeni uticaj na strukturu, resurse, programe obrazovanja. Da bi mogli da reaguju, njima su neophodni temeljni argumenti, što preciznije informacije o uzajamnom delovanju unutar vlastitog školskog sistema i njegovog odnosa sa drugim. Rezultati ovih studija, kao i njihova zvanična utemeljenost, treba planere obrazovanja i političare da stave u poziciju da učinak svog sistema obrazovanja uporede sa drugim kako bi ga bolje procenili i, potom, ponudili primerenije školsko-organizaciono-obrazovno-političke odluke (OECD-PISA, 2000). Ovo, takođe, znači i da te studije nisu smišljene da budu od praktično relevantne pomoći za nastavnike, te se nameće pitanje: da li nastavnici od takvih studija imaju neku korist?

\section{Razlike u postignuću na predmetima kao centar interesovanja}

Autori Internacionalne komparativne studije ispituju koje kompetencije usvajaju učenici za vreme školovanja, odnosno koji je ishod školskog procesa učenja i nastave. Postignuća koja učenici u proseku dosežu uzimaju se kao indikatori za to koliko dobro jedan školski sistem ispunjava svoju glavnu funkciju - a to je posredovanje 
određenih kvalifikacija. Dosadašnje studije baziraju se na ograničenom broju domena postignuća: postoje studije u kojima se izveštava samo i isključivo o stečenoj kompetenciji razumevanja pročitanog (,Reading Literacy", IGLU); druge se bave isključivo kompetencijama u matematici i prirodnim naukama (TIMSS); PISA analizira tri domena postignuća - čitalačku pismenost, matematiku i prirodne nauke, a CIVED se bavi istorijsko-političkim obrazovanjem. Zajedničko ovim studijama je da se svaka od njih odnosi na uži sektor stručnog (predmetnog) učenja. To, takođe, znači da postoje mnogi stručni prostori učenja nekog predmeta od stranih jezika, preko geografije i književnosti, do umetnosti, sporta i muzike, kojima se dosadašnje internacionalne komparativne studije nisu bavile. Ovo važi i za sve „ključne kompetencije” koje se oblikuju tokom školovanja, (od kooperativnosti do empatije, tolerancije, komunikativnosti, samodiscipline), i koje se nalaze u sadržajima predmeta (Andevski, 2003; Gojkov, Stojanović, 2015).

Internacionalne komparativne studije zahtevaju znatan metodološki napor, pre svega prilikom sastavljanja testova postignuća za svaki pojedinačni domen i uzrast (Baumert, 1997); zatim, ove testove treba da shvate učenici u trideset ili čak četrdeset različitih zemalja na isti način jer će se oni upoređivati na temelju istih kriterijuma. Pošto je takvo sastavljanje testova iz matematike jednostavnije za realizaciju od onih iz drugih predmeta (ovde postoje internacionalno usklađeni kurikulumi), najviše komparativnih studija je iz oblasti matematike (ibidem). Sastavljanje internacionalnih testova čitalačke pismenosti je veći problem, što se dobro može videti na primeru PISA studije. Najpre je trebalo sačiniti teorijski koncept „kompetencija čitalačke pismenosti” i podeliti ga na nekoliko dimenzija (Artelt, u.a., 2001). Tako je (na osnovu teorijskog i empirijskog aspekta) definisano pet nivoa kompetentnosti čitalačke pismenosti i u odnosu na ove nivoe (a time i postepeno smanjivanje nivoa težine) napravljeni su zadaci koji ne treba da sadrže kulturološke prepreke jer treba da ih shvate petnaestogodišnjaci u više od trideset država (od Srbije, preko Meksika, do Koreje). Zadaci su potom prevedeni na oko 25 različitih jezika, pri čemu nije smelo da dođe do promene sadržaja ili nivoa težine. Tek kada bi testovi ispunjavali ove zahteve dokazane na njihovim preliminarnim proverama, bilo je moguće primeniti ih i u okviru velikih, internacionalnih komparativnih istraživanja. 


\section{Izbor i poređenje zemalja}

Internacionalne komparativne studije postignuća učenika obuhvataju brojna istraživanja u kojima često učestvuje veliki broj zemalja. Jezgro tih zemalja je u Evropi, Severnoj Americi i Aziji. Ovoj grupi pripadaju, između ostalih, Engleska, Francuska, Belgija, Švedska, zatim Kanada i SAD, Japan i Južna Koreja, zemlje koje imaju visok nivo društveno-ekonomkog razvoja i raspolažu dobrim sistemom školstva. Socijalni uslovi ovih zemalja mogu se porediti sa zemljama koje su im kompatibilne svojim društveno-ekonomskim razvojem, i komparacija školskih sistema i ostvarenih postignuća između ovih zemalja ima smisla. Međutim, u komparativnim studijama učestvuju i oblasti i države koje su tek u procesu razvoja, npr. Južna Afrika, Tajland, Kolumbija, Brazil, zemlje u kojima ne postoji potpunije razvijen školski sistem. Zemljama koje se kompariraju pridružila se i Srbija, koja je još uvek u procesu tranzicije, sveobuhvatnih reformi i promena sistema vaspitanja i obrazovanja, te se pri upoređivanju rezultata ovih zemalja, posebno u kontekstu rangiranja, ne bi smele prevideti razlike koje postoje u društveno-ekonomskom razvoju i opštem standardu.

Zemlje koje učestvuju u istraživanjima obavezuju se da će se pridržavati metodoloških pravila i standarda koje je propisalo internacionalno rukovodstvo. Tako je, na primer, kod PISA studije 2000. godine najvažnije bilo sledeće:

- da se sprovede reprezentativno probno testiranje kod petnaestogodišnjaka i da se zemlje učesnice pridržavaju centralnih metodoloških pravila,

- pridržavanje određenog vremenskog okvira i strogo utvrđenih pravila sprovođenja istraživanja (anketiranja i testiranja),

- na najmanje $85 \%$ probnih testova treba postići rezultate koji se mogu proceniti.

Takva metodološka pravila treba čvrsto utvrditi kako bi realizovana istraživanja u različitim zemljama dala uporedive podatke utemeljene na produktivnom i fer poređenju.

Sa dobijenim rezultatima mora se pri poređenju pažljivo i informativno postupati. Upravo ovde često dolazi do pogrešnih zaključaka, naročito u postupku popularnog "rangiranja" (Rankings - postupanje sa tabelama rangova, koji se visoko kotiraju u javnoj diskusiji). Ovde treba obratiti pažnju na to da već i male razlike kod srednjih vrednosti vode ka 
različitom rangu, a da se sa tim ne mogu povezati značajne razlike između zemalja. Stoga je primerena i fer podela zemalja u grupe - na primer, zemlje koje imaju postignuće više od vrednosti OECD proseka, unutar OECD proseka i ispod OECD proseka (Baucal, Pavlović-Babić, 2013; Prenzel, u.a., 2007:84). Kod zemalja koje se nalaze u istoj grupi razlike $\mathrm{u}$ srednjim vrednostima nisu značajne, pa time $\mathrm{i}$ ispoljena razlika u rangu nije interpretabilna (Baumert, u.a., 1998). Relevantne razlike postoje samo kod zemalja iz različitih grupa, te je stoga neophodan kritički stav ako se posmatraju razlike od tri ili četiri ranga, ili se one čak i politički procenjuju i komentarišu.

Rezultati internacionalnih komparativnih studija imaju i široko rasprostranjenu obrazovno-političku interpretaciju koju treba sprovesti na temelju dobijene razlike u postignuću između zemalja na osnovu samo jednog, najuticajnijeg faktora. To mogu biti, na primer: podele na nivou srednjoškolskog sistema, stanje celodnevnog boravka u školi, broj časova nastave, izvođenje završnih ispita (matura) i drugo. U internacionalnoj komparaciji bolja ili lošija postignuća, zatim snažniji ili blaži procesi socijalnog sudelovanja - vraćaju nas na taj jedan faktor kojim se dalje obrazlažu obrazovno-politički zahtevi za unutrašnjost zemlje (na primer, izvođenje maturskih ispita). Ovo je često usko povezano sa namerom da se vlastitoj obrazovno-političkoj poziciji da naučni izgled. Ovakva argumentacija umesna je ne samo zbog toga što komparativne studije postignuća (kao studije proseka) principijelno ne dopuštaju sigurne zaključke o „uzrocima“. Ovde se uvek pronalaze - unutar trideset zemalja - ne samo primeri povezanosti nego i suprotni primeri: postoje visoka postignuća iz matematike u integrisanim školskim sistemima (Švedska), ali takođe i u podeljenom sistemu (Švajcarska) (Baumert\&Lehmann, u.a., 1997: 90); dobri rezultati u čitalačkoj pismenosti pronalaze se kako u zemljama sa niskim (Luksemburg), tako i u zemljama sa visokim brojem učenika u razredu (Kanada) (Bos, u.a., 2007: 53). Ukratko, zaključci sa nacionalnih rangiranja, dobijeni na osnovu navodnih uzroka, svakako mogu voditi zanimljivim pretpostavkama, ali se često ne mogu posmatrati kao naučni dokaz.

\section{Kritika standardizovanih komparativnih istraživanja}

Otkako postoji, komparativno istraživanje škola praćeno je kritikama. Pored angažovanog ali u isto vreme i krajnje ozbiljnog naučnog 
sukoba u vezi sa ovim studijama, veliki deo kritike je politički motivisan. Organizacije, savezi i stranke zainteresovani su pre svega za to da li određeni empirijski rezultati ovakvih studija popravljaju ili slabe njihove vlastite obrazovno-političke pozicije. U zavisnosti od toga, pojedina istraživanja se ili hvale ili kritikuju, a pomoću tobožnje kritike metode ne retko se pokušava prikriti vlastito političko-strategijsko ophođenje sa rezultatima istraživanja (Sprenger, 2000).

Naučna kritika komparativnih istraživanja bogata je kako načelnim, naučno-teorijskim i metodološkim prigovorima protiv upoređivanja sistema obrazovanja, tako i detaljnim kritičkim razmatranja pojedinih istraživačkih metoda. Jedna takva kritika upućena je prvi put sedamdesetih i osamdesetih godina protiv tadašnjeg (nacionalnog) komparativnog istraživanja sistema (Fend, 1982). Ona je ponovo oživela 2002. godine, ali je sada u centar postavljeno internacionalno komparativno istraživanje postignuća. Mogu se identifikovati tri tipične argumentacije, koje različito, „radikalno“ kritikuju komparativno istraživanje. U prvoj argumentaciji reč je o kompleksnosti obrazovnog procesa u školama da bi se načelno osporila snaga iskaza standardizovanih postupaka anketiranja i testiranja, sa objašnjenjem: „Škole imaju zadatak, da onima koji odrastaju daju obrazovanje koje će ih povezati sa osnovama naše kulture. Ovo se dešava u subjektivno različitim tokovima procesa prisvajanja. Takvo obrazovanje ne može se izraziti brojčanim vrednostima, a ni meriti kvantitativnim metodama" (Groeben, u.a., 2000: 6).

Takva kritika osporava da se standardizovanim postupcima testiranja uopšte može doći do relevantnih iskaza o obrazovnom procesu u školama. Konsekvenca ovakve kritike vodila je traženju sasvim druge forme pedagoških istraživanja, kao što je izvođenje kontekstno-senzibilnih studija slučaja na bazi kvalitativnih metoda (Döpp\&Groeben\& Thurn, 2002). Međutim, sa takvim istraživanjima, najčešće, nisu povezana internacionalna poređenja.

U drugoj argumentaciji nije, doduše, reč o generalnom osporavanju saznanja kvantitativnih metoda. Naprotiv, ovde se principijelno dovodi u pitanje mogućnost i smisaonost praktikovanja komparacije sistema: zato što pojedinačni školski sistemi, odnosno školske forme, rade u različitim kontekstima (uslovima), takva komparacija je često nefer ili čak irelevantna (Arnold, 1999). Ovo se, na primer, sreće kada testovi postignuća odgovaraju samo kurikulumu jedne određene školske forme (ili internacionalno samo nekim državama), a pri tom se mere, takođe, druge školske forme 
(ili države) sa drugačijom koncepcijom kurikuluma. Najzad, krajnje je problematično "kvalitet" jednog školskog sistema utvrditi isključivo na postignućima na nekoliko ključnih predmeta. Kod PISA studije, na primer, „mnoge važne ključne sposobnosti... ostaju po strani““ (Lind, 2004: 3), i prilično je ograničen spektar kompetencija koje se testiraju. Ovome treba dodati i sumnje koje su proizašle iz američkih istraživanja kada je bilo reči o školskim učincima komparativnih testova postignuća koji su doveli do sužavanja školskog kurikuluma na trening uvežbavanjem znanja za test a time i do marginalizacije, na primer, socijalnih i muzičkih kompetencija i sadržaja učenja (Nichols, Berliner, 2005; Schirp, 2006: 428). Kritičari su isticali da komparativna testiranja ubrzavaju institucionalnu prevaru i vode isključenju učenika sa slabim postignućima. Iako se ne mogu generalizovati otkrića ovih američkih istraživača u vezi sa komparativnim studijama postignuća, mora se primetiti da se ubrzavanjem postupka "teaching to the test" i briga nastavnika rasprostranila. Zbog ovakve kritike, neki pedagoški teoretičari i praktičari smatraju komparativne studije postignuća problematičnim sredstvom, koje svakako treba veoma dozirano primenjivati (Jahnke\&Meyerhöfer, 2007).

Dok navedene argumentacije načelno kritikuju standardizovano komparativno istraživanje, treća linija kritike prihvata ovo metodološko polazište. Polazeći od toga, postaje upitno da li u ovim studijama treba zadržati metodološke i statističke standarde empirijskih socijalnih istraživanja. Tako su neki autori skrenuli pažnju na probleme koji nastaju kada se testovi postignuća postave svim školskim formama (od osnovnih, preko stručnih škola do gimnazija) (Wottawa, 1987: 122). Često se dešava, da je komparacija podmirena samo na temelju oskudnih sposobnosti diferenciranja (ili obrnuto), tako da se navodno precizni rezultati komparacije često zasnivaju na nesigurnim metodološkim temeljima, te su zbog ovih problema komparativni rezultati TIMSS i PISA studija skeptički posmatrani (Klemm, 2002). Ali, ni sa ovom kritikom nisu potraženi metodološki drugačije postavljeni koncepti istraživanja; naime, često se težilo metodološkom optimizovanju unutar standardizovane paradigme upoređivanja.

Reakcije na ovu kritiku usledile su na različite načine. S jedne strane, "komparativni istraživači" oštro su reagovali i smatrali su je teorijski i metodološki neprikladnom (Baumert, Köller, Schnabel, 2000; Lind, 2000). Ali, paralelno s tim, već od TIMSS studije empirijski dizajn se kontinuirano poboljšavao, a usavršavane su i statističke analize, tako da 
je u metodološkom kvalitetu novijih istraživanja postignut napredak. I, kao treće, neki „komparativni istraživači” raspravljaju o sprovođenju studija slučaja o pojedinačnim školama kako bi se saznanja standardizovanih istraživanja proširila i produbila (Baumert\& Tillmann, 2005).

\section{Šta pružaju međunarodne komparativne studije?}

Važno pitanje koje prati internacionalne komparativne studije odnosi se na to koju korist sistem vaspitanja i obrazovanja ima njihovim realizovanjem. Postavlja se i pitanje koje su oblasti njihovog delovanja (na primer, obrazovna politika i javnost, delovanje nastavnika i školska praksa, istraživanja u oblasti vaspitanja i obrazovanja, teorija obrazovanja ...).

Razmatrane internacionalne komparativne studije postignuća, kako u IEA, tako i u OECD, temelje se, pre svega, na relevantnosti svih obrazovno-političkih odluka za pravni sistem. TIMSS i PISA treba primarno da daju precizne informacije onima koji upravljaju sistemom obrazovanja - ministrima, planerima obrazovanja - o jakim i slabim stranama nacionalnog sistema obrazovanja. Oni koji ,upravljaju“ u politici i administraciji time su u položaju da svoje obrazovno-političke odluke na nivou sistema (na primer, strukture u školama, odluke u okviru razreda, nastavni planovi) što racionalnije i jasnije postave. Postupak kojim se podupiru odluke donešene sa vrha školskog sistema, a na osnovu naučno dobijenih podataka, označava se kao „,upravljanje zasnovano na evidenciji” ili kao „koncept upravljanja zasnovan na evaluaciji” (Altrichter\&Heinrich 2006: 55) i već dugo se propagira kod onih koji razvijaju školski sistem i istražuju neophodnu modernizaciju procesa obrazovanja.

Povezano sa publikovanjem internacionalnih i nacionalnih PISA rezultata, brzo se pokazalo da su ministarstva prosvete u zemljama koje su učestvovale u istraživanju organizovala intenzivne aktivnosti na donošenju programa mera, javno predstavljenih kao primerena i brza reakcija na PISA rezultate. Pokazalo se da se ove mere nisu zadržale samo na nivou objave, nego su se na mnogim mestima razvile u stvarne aktivnosti.

\section{Zašto je PISA relevantna za sistem obrazovanja u Srbiji?}

Srbija je učešćem u PISA istraživanju dobila bogatstvo istraživačkih nalaza i stekla dokumentovanu sliku o nacionalnom sistemu obrazovanja. 
Podaci dobijeni empirijskim putem omogućili su donošenje odluka u vezi sa daljim razvojem sistema obrazovanja i unapređenjem postignuća učenika na nacionalnom nivou, kako na pojedinim segmentima procesa obrazovanja, tako i u okviru specifičnih grupa koje učestvuju u obrazovanju. Omogućeno je poređenje podataka sa drugim zemljama učesnicima, te dodatne informacije o postignućima i mogućnostima nacionalnog sistema obrazovanja. Olakšano je i dugoročno planiranje razvoja obrazovnog sistema s obzirom da generacije koje se sada školuju u Srbiji već pripadaju evropskom prostoru obrazovanja. Kako će ovi mladi ljudi svoje odraslo doba proživeti verovatno kao građani EU, obaveza obrazovnog sistema Srbije je da obezbedi postignuća koja će biti konkurentna širim okvirima nego što je nacionalni.

PISA studijom nastoji se utvrditi veza koja postoji između obrazovanja i nacionalnih ekonomija; stoga ispituje i promoviše znanja i veštine neophodne iz perspektive snalaženja na tržištu rada $i$ vođenju karijere, a uspostavljanje direktnije veze između zahteva tržišta, privrede i obrazovanja u fokusu je naših intencija koja se tiču obrazovnog sistema. PISA je dobar model koji demonstrira kako se ta veza uspostavlja na nivou očekivanih obrazovnih postignuća. Relevantnost znanja i veština koje se mere u PISA studiji potvrđena je i u istraživačkim studijama kojima su praćeni akademski i profesionalni razvoj mladih ljudi posle njihovog učešća u PISA istraživanju. Longitudinalne studije realizovane u Australiji, Kanadi i Švajcarskoj pokazuju izrazitu pozitivnu korelaciju između postignuća ostvarenog u čitalačkoj pismenosti i kasnijeg akademskog uspeha i uspeha na tržištu rada.

\section{PISA istraživanja i školska praksa}

Kada se nastavnici bave internacionalnim komparativnim studijama postignuća, tada sebi postavljaju pitanje: koja je relevantnost ovih studija za moju vlastitu školsku praksu? U kojoj meri one doprinose rasvetljavanju i poboljšanju odnosa i stanja u školi? Da li se iz njih mogu dobiti podsticaji za unapređivanje rada nastavnika u vlastitoj školi? Prvi sistematičan odgovor na ova pitanja glasi: internacionalne komparativne studije formulišu svoje iskaze isključivo na nivou školskih sistema i povezanosti koje su u okviru njih nastale. Jedan takav iskaz, utemeljen u ravni sistema, može da glasi približno ovako: što se ranije deca u jednom školskom sistemu podele na različite školske forme, to je oštrija socijalna podela (diferencijacija) 
(Baumert\&Artelt, 2003: 190). Empirijska sposobnost PISA istraživanja ne dopušta da se formulišu odgovarajući iskazi (ovde: mera socijalne podele/ diferencijacije) niti na nivou pojedinačne škole niti čak jednog razreda. $\mathrm{Na}$ osnovu ovog ograničenja, učestvovanje neke škole u PISA studiji (ili u nekoj drugoj internacionalnoj komparativnoj studiji) ne sme se zameniti evaluacijom te škole. Na temelju internacionalne komparacije postignuća, zbog toga se ni ne rangiraju škole niti iskazi o kvalitetu pojedinačnih škola i razreda. Sa geldišta naučnika koji učestvuju u ovom procesu ovo je sasvim konsekventno, ali iz aspekta učenika i nastavnika koji učestvovuju u takvim studijama, sve dobija drugu dimenziju, jer sami žele da saznaju više o svom radu kako bi ga eventualno mogli poboljšati.

Zbog toga navodimo dilemu između metodološke ograničenosti internacionalnih komparativnih studija, sa jedne strane, i opravdanih zahteva škola učesnica za povratnim informacijama, sa druge. Kako se istraživači ophode sa ovom dilemom - videće se na primeru PISA 2000.

\section{Povratne informacije kod međunarodnih uporednih studija znanja}

U internacionalnim komparativnim studijama učestvuju uvek škole koje su slučajno izabrane u okviru test probe. Kod PISA studije test proba vrši se na učenicima koji imaju 15 godina i koji ispunjavaju anketu i test. Prvi rezultati objavljuju se u intervalu od 18 do 24 meseca kasnije. Otprilike u isto vreme škole koje su učestvovale informišu se u kratkom izveštaju najpre o uopštenim rezultatima internacionalne komparativne studije znanja. Ovde su u pitanju rezultati na nivou sistema, koji su detaljno ispisani u velikim sabranim izveštajima, ali se školama šalje sažet rezime. Može se pretpostaviti da neki od ovih rezultata podstiču refleksiju situacije u vlastitim školama.

Jedan takav iskaz može da probudi interese nastavničkog kolegijuma da sa te tačke gledišta bolje osmotri situacija u vlastitoj školi i da se potraži da li se generalne povezanosti (odnosi) sreću u tamošnjoj školi. Time rezultati opšte analize postaju relevantni za praksu konkretne škole (mada davanje povratne informacije svakoj školi pojedinačno i nije svrha realizacije ovih međunarodnih studija). Istraživači PISA studije potrudili su se da povratne informacije sa individualnim školskim podacima daju za sve škole (njih otprilike 1500). Takve povratne informacije mogu, na primer, ovako da glase: „Učenici vaše škole imaju u oblasti čitalačke pismenosti srednju vrednost na testu, koja iznosi 485 bodova. Srednja vrednost 
testa za škole sa komparativnim učenicima iznosi 509 bodova. Srednja vrednost vaše škole nalazi se značajno ispod vrednosti, koje su ostvarile škole sa komparativnim učenicima" (Stanat, 2002: S.IV). Nastavnički kolektiv dobija individualne podatke za školu, doduše u formi povratne informacije, ali se u isto vreme nedvosmisleno skreće pažnja na to da su ovi podaci ograničavajući. Ovu povratnu informaciju o rezultatima zato ne treba shvatiti kao evaluaciju, nego samo treba da služi kao „podsticaj za jedan profesionalni razgovor o školi i nastavi“ (ibidem). Ovo svakako ne može biti opcija zbog toga što se ti „razgovori“ vode samo u školama iz uzorka, a to je samo malo preko $10 \%$ škola na teritoriji države. Na Slici 1 prikazani su uporedni rezultati PISA testiranja za period 2003-2012 u odnosu na matematičku pismenost.

Prosečni nivo matematičke pismenosti petnaestogodišnjaka iz Srbije na skali PISA 2012. iznosi 449 poena. U ovom postignuću učenika iz Srbije može se primetiti skromno poboljšanje od 7 poena u odnosu na prethodno testiranje. Ukratko: rezultati učenika iz Srbije su i dalje ispod OECD proseka, dok se kod vodećih zemalja malo šta promenilo.

\begin{tabular}{|lccccc|}
\hline Srbija & 2003 & 2006 & 2009 & 2012 & Razlika 2012 i 2009 \\
\hline Hrvatska & 437 & 435 & 442 & 449 & +7 \\
\hline Slovenija & -- & 467 & 460 & 471 & +11 \\
\hline Crna Gora & -- & 504 & 501 & 501 & 0 \\
\hline Bugarska & -- & 413 & 428 & 439 & +7 \\
\hline Rumunija & -- & 415 & 427 & 445 & +18 \\
\hline Albanija & -- & -- & 377 & 394 & +17 \\
\hline
\end{tabular}

\section{Istraživanje u pedagogiji i teoriji obrazovanja}

Diskusije o rezultatima internacionalnih komparativnih studija ukazuju na povećan javni značaj empirijskih istraživanja obrazovanja i njegovih aktera. Političari u oblasti obrazovanja sve češće se pri utemeljenju svojih pozicija i predloga pozivaju na PISA studije i ostale studije koje ih prate. Empirijski istraživači, takođe, češće nego ranije učestvuju u javnim diskusijama o obrazovanju i njegovom daljem razvoju i snažno su prisutni kako u štampi tako i u obrazovno-političkim savetodavnim telima. Ipak, 
ovde nije reč samo o porastu uticaja i značaja, nego takođe i o jednom masovnom institucionalnom izgrađivanju povezanim sa značajnim dobijanjem određenih resursa.

Ukratko, već sa prvim PISA knjigama, člancima, publikacijama, postignut je izvestan dobitak u saznanju koji ima visoku relevantnost unutar nauke. Dolazimo do toga da PISA istraživači svoje podatke diferenciranije analiziraju u jednom drugom talasu ocenjivanja i bave se pritom pitanjima koja su, pre svega, disciplinarna (psihologija, pedagogija...), a samo mnoštvo i tematska specifikacija ovih rezultata čini jasnim da politika obrazovanja nije bila zamišljena kao njihov glavni korisnik. Štaviše, reč je o tematski različitim analizama koje ulaze kao saznanja istraživanja obrazovanja u naučni diskurs (Baucal, Pavlović-Babić, 2010; 2013).

\section{Zaključak}

Internacionalne komparativne studije postignuća su itekako u stanju da identifikuju problemska polja i tako pokažu potrebe delovanja. Ipak, iz njihovih podataka još uvek se ne izdvajaju neposredna uputstva za delovanje u pedagoškoj praksi. Konkretno, na osnovu izuzetno niskih vrednosti kompetencija čitalačke pismenosti ili matematičke pismenosti, ne daje se nikakav program mera za njihovo unapređenje. Kada se sledi jedan takav - prema praksi orijentisan interes iskorišćavanja - mora se okrenuti drugim formama pedagoških istraživanja, na primer, na eksperimentalne studije istraživanja nastave ili na rezultate istraživanja koja se bave praksom nastave i delovanja na nastavu.

$\mathrm{Na}$ samom kraju, možemo zaključiti sledeće: kada je reč o PISA, TIMSS i ostalim „,large-scale-assessement“ studijama, u Srbiji je podstaknuto interesovanje za empirijska istraživanja obrazovanja. Istovremeno, došlo je do porasta empirijskih znanja, kako u našem školskom sistemu, tako i u strukturi kompetencija u određenim domenima (čitalačka pismenost, matematika...). Ovo znanje ulazi, pre svega, u naučni diskurs u oblasti obrazovanja i vaspitanja, u pedagogiju i psihologiju, te učestvuje u oblikovanju didaktike i metodika. Može se konstatovati da ni politika obrazovanja ni školska praksa ne postaju inicijatori daljeg mogućeg razvoja, nego su to, pre svega, sama istraživanja u oblasti obrazovanja.

Internacionalne komparativne studije postignuća, što važi kao nesporno, daju različite informacije o našem školskom sistemu u poređenju sa školskim sistemima drugih država, i to ne samo o postignućima iz 
nekog predmeta, nego, između ostalog, i o socijalnoj selekciji, razlikama između polova, o vremenu za učenje i nastavu i drugo. Na osnovu ovih studija, došlo se do primetno više znanja o školi kao sistemu, čemu su posebno doprinele pretpostavke i uverenja koja su empirijski i dokazana, te se tako oblikuju i problemska dijagnoza i zahtevi za pomoć. U Srbiji je pokazano da su niski PISA rezultati imali znatan uticaj na obrazovnopolitičke procese, te je ova studija probudila interes javnosti za školu i obrazovanje i na taj način unapredila status same politike obrazovanja. To nikako nije predviđeno konceptom PISA studije, ali se unosi kao pomak ka oblikovanju nove, demokratske kulture.

\section{WHAT IS OFFERED BY INTERNATIONAL COMPARATIVE STUDIES}

\section{SUMMARY}

Abstract: International, empirical comparative studies, which have been implemented in recent years, are better known under the abbreviations: PISA, TIMSS, IGLU, CIVED, „Reading Literacy”. These studies examine primarily results, performance (output), and the students' achievements in the different national school systems. The paper discusses the possibilities and limits provided by these international comparative studies of achievement, their fields of work, methodical starting points that accompany them, the problems, as well as the benefits provided by these studies, by which we understand the reflection in public, school and teaching practice, and implications for further research in the field of education, and theories of education. The results of these studies should primarily put ministers, education planners, and politicians in a position to compare the effects of their education system with others, in order to better assess the strengths and weaknesses of the national education system, and then, offer more appropriate school-organizational and educational policy decisions.

Key words: international comparative studies, achievement, education system. 


\section{Literatura}

Altrichter, H., Heinrich, M.(2006). Evaluation als Steuerungsinstrumente im Rahmen eines „neuen Steuerungsmodells“ im Schulwesen. In: Böttcher, W., Holtappels, H.G., Brohm, M.(Hrsg.) Evaluation im Bildungswesen. Weinheim, S. 51-64.

Andevski, M. (2003). Pedagoška kompetentnost u novom društvenom diskursu. Naučni skup sa međunarodnim učešćem, Obrazovanje $i$ usavršavanje učitelja (185-195). Užice: Učiteljski fakultet.

Arnold, K.H. (1999). Fairneß bei Schulsystemvergleichen. Münster.

Artelt, C., Stanat, P., Schneider, W., Schiefele, U. (2001). Lesekompetenz:

Testkonzeption und Ergebnisse. In: Baumert, J. U.A. (Hrsg.) (2001).

PISA 2000. Basiskompetenzen von Schüle- rinnen und Schülern im internationalen Vergleich. S.69-140.

Baucal, A. i Pavlović-Babić, D. (2010). Nauči me da mislim, nauči me da učim. Beograd: Institut za psihologiju Filozofskog fakulteta u Beogradu - Centar za primenjenu psihologiju.

Baucal, A. i Pavlović-Babić, D. (2013). Podrži me, inspiriši me. Beograd: Institut za psihologiju Filozofskog fakulteta u Beogradu - Centar za primenjenu psihologiju.

Baumert, J., Lehmann, R. (1997). TIMSS- Mathematischnaturwissenschaftlicher Unterricht im internationalen Vergleich. Deskriptive Befunde. Opladen.

Baumert,J.,Bos,W.,Watermann,R.(1998). TIMSS-Mathematiscnaturwisse nschaftlicher Unterricht im internationalen Vergleich. Deskriptive Befunde. Opladen.

Baumert, J., Köller, O., Schnabel, K.U. (2000). Schulformen als differentielle Entwicklungs-milieus eine ungehörige Fragestellung? In: Gewerkschaft Erziehung und Wissenschaft (Hrsg.).Messung sozialer Motivationen-eine Kontroverse. Frankfurt/M.S.28-68.

Baumert, J., Artelt, C. (2003). Bildungsgang und Schulstruktur. In: Pädagogische Führung, 4; S.188-192.

Baumert, J., Tillmann, K.J. (2005). Vorwort. In: Watermann, R., Thurn, S., Tillmann, K.J., Stanat, P. (Hrsg.).Die Laborschule im Spiegel ihrer PISA-Ergebnisse. Weinheim, S.9-11.

BMBF: Bundesministerium für Bildung und Forschung (2007). Rahmenprogramm zur Förderung der empirischen Bildungsforschung. Berlin.

Bos, W., Hornberg, S., Arnold, K.-H., Faust, G., Fried,L.,Lankes,E.M.,Schwippert,K., Valtin,R.(Hrsg.)(2007).IGLU2006-Lesekompetenz 
von Grundschulkindern im internationale Vergleich. Münster.

Döpp, W., v.d. Groeben, A., Thurn, S. (2002). Lernberichte statt Zensuren.

Erfahrungen von Schülern, Lehrern und Eltern. Bad Heilbrunn.

Fend, H. (1982). Gesamtschule im Vergleich. Bilanz der Ergebnisse des Gesamtschul-versuchs. Beltz Weinheim.

Gojkov, G., Stojanović, A. (2015). Didaktičke kompetencije $i$ Evropski kvalifikacioni okvir. Beograd, SAO.

Groeben, A. Von der u.a. (2000). Schulen für ein neues Verständnis von Leistung und Qualität. In: Pädagogik, 52, Heft 12. S. 6-7.

Jahnke, Th., Meyerhöfer, W. (Hrsg.) (2007). PISA und Co. Krittik eines Programms. Hildesheim.

Klemm, K. (2002). Schau genau. Wie stark sind die Leistungsschwächern.

Es gibtZweifel an den PISA-Ergebnissen aus Bayern. In: Süddeutsche Zeitung. 3. 9. 2002. S. 23.

Lind, G. (2000). Zur Messung sozialer Motivationen in der BIJU-Studie. In: Gewerkschaft Erziehung und Wissenschaft (Hrsg.) Messung sozialer Motivationen - eine Kontroverse, Frankfurt/M. S. 9-27.

Lind, G. (2004). Jenseits von PISA - für eine neue evaluationskultur. In: Institut für Schulent- wicklung (Hrsg.). Standards, Evaluation und neue Methoden. Reaktionen auf die PISA-Studie. Hohengehren. S. 1-7.

Nichols, S. L.,Berliner, D. S. (2005). The Inevitable Corruption of indicators an Educators Through High-Stakes Testing. Arizona State University (EPSL). Temple.

OECD-PISA (2000)(Hrsg.).Schülerleistungen im internationalen Vergleich.Eine neue Rahmenkonzeption für die Erfassung von Wissen und Fähigkeiten. Max-Planck-Institut für Bildungsforschung, Berlin.

Prenzel, M., Artelt, C.,Baumert,J.,Blum,W.,Hammann,M.,Klieme,E., Pekrun,R.(2007) (Hrsg.). PISA 2006- die ergebnisse der dritten internationalen Vergleichsstudie. Münster/W.

Schirp, H. (2006).Zentrale quantitative Leistungsmessungen und qualitative Schulent- wicklung. Die Wirkung von High Stakes Tests in den USA. In: Die Deutsche Schule, 98. Jg., Hegt 4. S. 422-435.

Sprenger, U. (2000). Die unterschiedlichen Fördereffekte der verschiedenen Schulfor- men. In: Bildung aktuell, 51. Jg., Heft 5. S. 22-23.

Stanat,P.,u.a.(2002)(Hrsg.).Rückmeldung der PISA2000-Ergebnisse an die beteiligten Schulen. Max-Planck-Institut für Bildungsforschung, Berlin.

Tillmann, K.-J. (2011). Was Internationale Vergleichsstudien leisten. In: Moser, H., (Hrsg.) Forschung in der Lehrerbildung. Baltmannsweiler. 
Schneider Verlag Hohengehren.

Weiß, M.,Timmermann, D.(2008). Bildungsökonomie und Schulstatistik. In: Helsper, W., Böhme, J.(Hrsg.).Handbuch der Schulforschung, 2. Aufl., Wiesbaden.S. 239-284.

Wottawa, H. (1987). Konzepte der Testkonstruktion und ihre Anwendung bei Schulsystemvergleichen-Möglicheiten, Probleme und Grenzen der klassischen und probabi- listischen Testtheorie. In: Aurin, K. (Hrsg.). Schulvergleich in der Diskussion. Stuttgart, S. 122-136. 